\title{
Psychological underpinnings of metabolic syndrome
}

\author{
Barbara J. Stewart-Knox \\ Northern Ireland Centre for Food and Health (NICHE), University of Ulster, Coleraine BT52 ISA, UK
}

\begin{abstract}
Metabolic syndrome (MS) is more common among socio-economically disadvantaged individuals and is associated with certain risky lifestyle practices. MS also appears to be triggered by adverse social circumstances and chronic stress. The present paper reviews accumulating evidence to imply that individuals who have certain personality and behaviour traits are particularly predisposed to develop MS, and brings together theories that relate to possible psychological mechanisms underlying MS. It considers how such factors might interact causally to encourage the development of MS. As part of the EU-funded LIPGENE Integrated Project, multi-level modelling will be undertaken to explore potential pathways to MS, taking into consideration the interplay between a range of psycho-social, demographic, cultural and lifestyle factors thought to contribute to the development of MS. Data will be gathered for this purpose from a representative sample of $>50$-year-olds living in Britain ( $n$ 1000) and Portugal ( $n$ 500). It is anticipated that this information will assist in the development and targetting of future intervention to prevent and treat MS in the normal population.
\end{abstract}

Metabolic syndrome: Psychological: Social: Demographic: Cultural

Obesity is a growing problem in Europe, currently affecting between 10 and $20 \%$ of the population (Buttriss, 2003). Understanding the various factors that have contributed to this trend and understanding why obesity is so difficult to treat has become an increasingly important health issue. The metabolic syndrome (MS; also known as syndrome $\mathrm{X}$, insulin resistance syndrome, dysmetabolic syndrome, deadly quartet and plurimetabolic syndrome) is a cluster of factors associated with increased risk of developing CHD and/or type 2 diabetes. MS comprises insulin resistance (fasting blood sugar $>10 \mathrm{mg} / \mathrm{l}$ ), dyslipidaemia (triacylglycerol $\geq 15 \mathrm{mg} / \mathrm{l}$, HDL $<4 \mathrm{mg} / \mathrm{l}$ for men and $5 \mathrm{mg} / \mathrm{l}$ for women, LDL $>15 \mathrm{mg} / \mathrm{l}$ ), essential hypertension (blood pressure of $\geq 130 \mathrm{mmHg}$ for systolic and $\geq 85 \mathrm{mmHg}$ for diastolic) and visceral obesity (waist circumference of $>1020 \mathrm{~mm}$ for men and $>890 \mathrm{~mm}$ for women; Meigs et al. 1997; Roth et al. 2002).

MS, which is an antecedent of heart disease and type 2 diabetes, appears to be partly hereditary, may have its roots in early childhood, tends to develop with age and is exacerbated by poor diet and sedentary lifestyle (Raikkonen et al. 2003). There is substantial evidence to suggest that the condition is lifestyle related (McCaffery et al. 2003) and, if noticed early enough, can be reversed through dietary change and increased physical activity (Roth et al. 2002). Both large cross-sectional studies (Paffenbarger et al. 1978; Rennie et al. 2003) and longitudinal studies (Laaksonen et al. 2002, 2003) have shown that MS is less common among those individuals who take regular vigorous and moderate physical exercise and who eat a healthy diet (Lidfeldt et al. 2003). Lifestyle is only one among many factors that may contribute to risk for MS and consequently CHD and type 2 diabetes. MS may also be characterised by certain psychological traits and behaviours, emotional states and social circumstances. If the association between MS and these factors is verified, other new possibilities will emerge for successful intervention to prevent and treat MS before CHD and type 2 diabetes actually develop.

There is substantial evidence for a psycho-social component in the aetiology of CHD and emerging evidence that psychological factors may also contribute to the development of type 2 diabetes (Niaura, 2002). Stress (both acute and chronic), certain psychopathologies and adverse social conditions appear to be associated with increased risk of CVD (Kiecolt-Glaser et al. 2002). There is also growing evidence in recent literature that implies that MS may be triggered and/or exacerbated by adverse

\footnotetext{
Abbreviation: MS, metabolic syndrome.

Corresponding author: Dr Barbara J. Stewart-Knox, fax +44 2870324 965, email b.knox@ulster.ac.uk
} 
social factors (Horsten et al. 1999) and certain psychological pathologies (Kinder et al. 2004), traits and behaviours (Raikkonen et al. 2003). Based on this interrelationship, intervention to reduce psychological distress could avoid the development of MS and potentially prevent or retard subsequent development of CHD and type 2 diabetes in susceptible individuals and groups. It is, therefore, becoming increasingly important to establish the extent to which psychological factors contribute to MS. The purpose of the present mini-review is therefore to explore existing recent literature to assist in generating hypotheses for further study to determine and explore interrelationships between relevant psychological and social drivers of obesity and MS and related disease outcomes.

\section{Could metabolic syndrome be triggered and/or exacerbated by psycho-social factors?}

The role of negative emotions in the development of CHD is well established. The term 'type A' was originally coined by Friedman \& Rosenman (1959) to refer to what they postulated to be a 'coronary-prone' behaviour pattern. The type A pattern is characterised by competitiveness, time urgency, impatience and hostility. Individuals with a type A pattern have been described as aggressive, dominant, quick-witted, self-confident, autonomous and extraverted. The trait is measured using the Minnesota Multiphasic Personality Inventory-derived Scale (Cook \& Medley, 1954). Hostility, which is part of what comprises the type A pattern, has been defined as a mixture of anger and disgust often accompanied by indignation, contempt and resentment (Plutchik, 1980). Hostility appears to be stable over a period of time (Woodall \& Matthews, 1993), suggesting that it could in itself be considered a trait. Anger, on the other hand, is a state of arousal that comprises behavioural, subjective, visceral and somatic components, and has been defined as the 'urge to attack' and as 'the opposite of fear' (Danesh, 1977). Anger is commonly assessed using the Trait Anger Questionnaire and the Anger Expression Scale (Spielberger, 1983). Both hostility and anger are commonly observed among those with high blood pressure and are associated with increased risk of heart disease (Haynes et al. 1980; Niaura, 2002).

Clinical features of MS are commonly observed among those individuals with a type A coronary-prone behaviour pattern (Ravaja et al. 1996). MS and CHD may, however, have different psychological precursors. Several studies have considered hostility and anger in relation to various anthropometric and biochemical markers for MS. Obesity and insulin resistance appear to be consistently related to hostility through childhood (Raikkonen et al. 2003). Associations between hostility and clinical features of MS, however, become less tenuous in adulthood. Earlier research by the same group (Raikkonen et al. 1996) has considered anger, hostility and type A behaviour as well as tiredness in Finnish middle-aged males $(n 90)$ in relation to anthropometric, demographic and lifestyle practices, and has found no associations between type A behaviour or hostility and any of the metabolic factors associated with MS. Waist:hip ratio was, however, found to be related to high exhaustion and anger expression. A more recent study, which includes both male and female middle-aged civil servants and is part of the Whitehall II study (Feldman \& Steptoe, 2003), has also found no relationship between markers of impaired glucose metabolism and hostility. Only one study (Niaura et al. 2000) appears to have found evidence of hostility in males with MS. Together the evidence suggests that there may be gender differences in the way psychological and metabolic factors interact in MS. A longitudinal cohort study of middle-aged women has indicated increased risk of MS among those who experience high levels of anger (Raikkonen et al. 2002). Further evidence that negative emotions could be particularly detrimental to women's health comes from a study that used computed tomography scanning (Raikkonen et al. 1999a,b). This study indicates that hostility and anger contribute to visceral adipose tissue to a similar extent to smoking, alcohol or lack of physical activity in post-menopausal women. Current knowledge therefore implies that hostility may be particularly detrimental to women's health.

Chronic stress (Bjorntorp \& Rosmond, 1999; Waldstein et al. 1999; Bjorntorp, 2000; Brunner et al. 2002; Vitaliano et al. 2002; Steptoe \& Marmot, 2003) and stressful life events (Ravaja et al. 1996) have been linked to the development of abdominal obesity. Abdominal obesity is also commonly observed among sufferers of clinical depression (Weber-Hamann et al. 2002; McElroy et al. 2004), as well as in depressed (McCaffery et al. 2003; Kinder et al. 2004) and anxious (Landen et al. 2004) nonclinical populations. Depression may be more deleterious to women's health than to men's health. A large population study ( $n$ 3186; Kinder et al. 2004) has found a higher incidence of MS among young women (but not men) with a history of depression when other factors associated with MS are controlled. Features of MS also appear more common among women experiencing social anxiety (Landen et al. 2004). Again, this finding suggests gender differences in how MS develops and underlines the importance of including both genders in research exploring obesity in chronic disease pathways. Existing research, therefore, implies the possibility of different genderspecific causal pathways to MS.

Socio-economic deprivation has been shown to increase with age and to be associated with greater ill health in later years (Frost et al. 2001). Clinical features of MS are more commonly observed among more socio-economically disadvantaged individuals (Bjorntorp, 2000), in individuals who have spent less time in education (Wamala et al. 1999; Kerenyi et al. 2000; Hidvegi et al. 2001; Lidfeldt et al. 2003) and in those doing more menial jobs (Brunner et al. 1997). Coronary-prone behaviours such as hostility may to some extent explain social-class differences in health. Large population studies have observed the highest levels of hostility among individuals in the lower social classes, especially in older subjects (Barefoot et al. 1991; Niaura et al. 2000). Meanwhile, these findings may reflect a greater extent of social stress being experienced by individuals who are socio-economically disadvantaged. 
The social environment in which the individual interacts is also likely to have consequences for health and psychological well-being, and subsequent development of MS. Individuals who lack social support and/or those who are socially isolated are more likely to develop MS, irrespective of social status (Woodall \& Matthews, 1993; Horsten et al. 1999; Bjorntorp, 2000; Feldman \& Steptoe, 2003). Social support, therefore, may mediate any adverse effect of social circumstances.

Whether psychological and social factors are an antecedent or a consequence of ill health, however, remains to be established. Psychological distress, social circumstances and lifestyle are likely to interact to increase the risk of MS. Adverse social conditions may lead to or be brought about by unhealthy lifestyle practices. It is possible that a tendency towards hostility and anger, as well as disadvantaged social circumstances, may lead to and/or are triggered by detrimental lifestyle practices. Unhealthy lifestyle practices and adverse social environments may therefore elicit negative psychological responses and/or vice versa in susceptible individuals to bring about MS. Implying different pathways to MS, a study that has compared elderly caregivers with similar non-caregivers has found a direct link between psychological distress and $\mathrm{MS}$, in addition to one mediated by lifestyle (Vitaliano et al. 2002). It was concluded that stress is exacerbated by lack of social support and/or poor coping skills. Negative psychological traits and states may thus bring about or be brought about by unhealthy lifestyle practices and/or adverse social circumstances.

\section{How does psycho-social stress lead to the development of metabolic syndrome?}

The specific nature and scope of different relevant psychological and physiological mechanisms and how they bring about MS is currently unknown (Muldoon et al. 2004). Those individuals with a type A behaviour pattern typically respond to laboratory-generated challenges with exaggerated sympathetic nervous system reactivity (Diamond, 1982; Puttonen et al. 2003), implying that such individuals may be particularly prone to suffer stress. Chronic stress has been shown to be associated with visceral obesity and MS (Bjorntorp, 1999; Bjorntorp \& Rosmond, 1999; Brunner et al. 2002; Vitaliano et al. 2002; Steptoe \& Marmot, 2003). To explain how this association could occur, it is suggested that MS may be the result of a stress-induced cortisol-mediated acute inflammatory immune response (Kiecolt-Glaser et al. 2002; Black, 2003; Seematter et al. 2004). Chronic inflammation has been associated with CVD and type 2 diabetes (and also periodontal disease and arthritis). The finding that depression and anxiety both appear to have the ability to trigger the release of pro-inflammatory cytokines (proteins that are normally released and signal to other cells in response to infection or injury) provides some support for this argument (Kiecolt-Glaser et al. 2002).

\section{The cortisol hypothesis}

Cushing's disease, which is the result of increased adrenal secretion of corticosteroids, is often referred to in evidence for the involvement of cortisol in the development of MS. Similar to MS, Cushing's disease is characterised by visceral fat deposition, hypertension, hyperlipidaemia, depression and hypercortisolaemia (Bjorntorp, 2000; Brown et al. 2004). There is further evidence to support the involvement of cortisol in the development of MS. Individuals treated with steroids tend to put on weight (Bjorntorp, 2000). Also, there are associations between high salivary cortisol and anthropometric (Wallerius et al. 2003; Ward et al. 2004) and other measures of MS, such as blood pressure and lipid profile (Rosmond et al. 2000), which are consistently observed in older men. Metabolic response to stress is, however, likely to be dependent on both the sympathetic nervous system (flight and fight response) and the hypothalamic-pituitary-adrenal axis (defeat response) (Bjorntorp, 2000). According to this view, stress that is induced by adverse social conditions may trigger neuroendocrine change in two possible ways: first, through the release of the catecholamine neurotransmitters adrenaline and noradrenaline, both of which can bring about an increase in blood pressure in response to sympathetic nervous system activity. Whereas both adrenaline and noradrenaline bring about peripheral vasodilation to enable anxiety and flight, noradrenaline alone brings about peripheral vasoconstriction to enable anger and fight (Diamond, 1982); second, stress-induced hypothalamic arousal is specifically thought to activate adrenocortisol secretion, thereby bringing about increased fat deposit and MS (Brindley, 1995; Bjorntorp \& Rosmond, 2000; Drapeau et al. 2003). Hypothalamic-pituitary-adrenal axis activity is controlled through negative feedback from glucocorticoid receptors in the hippocampus area of the brain, which are believed to homeostatically control blood pressure and insulin and glucose levels, in response to stressors. Chronic activation of the hypothalamic-pituitaryadrenal axis may eventually impair this negative feedback system (Bjorntorp, 2000). This mechanism may be reciprocal, given that sympathetic nervous system activity is increased by eating and decreased by fasting (Bjorntorp, 2000). Visceral fat, in turn, may release cytokines, which stimulate hypothalamic activity to further increase stress (Drapeau et al. 2003). In keeping with this idea, high levels of noradrenaline have been associated with the release of leptin (Eikelis et al. 2004). Leptin is an adipocyte hormone that appears to be released in greater quantities in obese individuals (Oppert et al. 1997). Leptin is released from fat and is believed to signal other neurochemicals, including the catecholamines, to become active in the central nervous system (Halford, 2001). Thus, it is possible that leptin stimulates sympathetic nervous system activity (Esler et al. 2001) to mediate glucose and fat metabolism (Nonogaki, 2000).

\section{The serotonin hypothesis}

Links between abdominal obesity and depression suggest dysregulation of serotonin activity that could potentially predispose certain individuals to MS. Further evidence for a role for serotonin in the development of MS comes from studies that have observed response to serotonin agonists. Despite some evidence to suggest that serotonin agonists 
(including the commonly-prescribed selective serotonin reuptake inhibitors) can curb hunger and reduce body weight in the short term (Sargent et al. 1997), prolonged use of such drugs seems to induce MS (Baptista, 1999; Zimmermann et al. 2003; Almeras et al. 2004; Basu et al. 2004; Vieta, 2004). Both animal (Roy et al. 2004) and human research (Eikelis et al. 2004) has implied that enhanced serotonin turnover could be linked to the development of obesity. Amphetamine-like anorexic drugs such as fenfluramine and dexfenfluramine are thought to act by inhibiting re-uptake of serotonin at the central nervous system synapse, thereby enhancing and prolonging its action (Wellman et al. 2003). In speculating how enhanced serotonin activity might bring about obesity, it has been suggested that serotonin interplays with leptin and cortisol in producing stress-induced body-weight gain. Intravenous administration of a selective serotonin re-uptake inhibiter has been shown to increase plasma leptin levels and cortisol response to a greater extent in obese women than normal-weight women (Oppert et al. 1997). Serotonin activity has not only been implicated in the development of visceral fat but also in the development of other metabolic factors associated with MS. Elevated triacylglycerols, hypertension and insulin resistance have been found to be associated with lowered fenfluramine-released prolactin response (a proxy for serotonergic activity), providing further evidence for enhanced serotonin activity in the development of MS (Muldoon et al. 2004). There is, therefore, good reason for presuming that serotonin has a role in the psychology of obesity and MS. The notion that metabolic change could be serotonin mediated implies the usefulness of undertaking further research to explore the importance of psychological factors assumed to be linked to enhanced serotonin activity in relation to visceral obesity and MS.

\section{Can risk for metabolic syndrome be predicted from anthropometric measures alone?}

Large population research as part of the EU-funded LIPGENE Integrated Project will explore a novel range of potential psychological triggers of MS. A quick easilyassessed non-invasive marker of MS will be required for this purpose. Clinical characteristics of MS such as midsection obesity, high blood pressure, cholesterolaemia and insulin resistance appear to be both collectively and individually predictive of cardiovascular risk (Lawlor et al. 2004). Clinical features indicative of MS appear to vary in how well they predict each other and consequent risk for MS. Anthropometric assessment may provide a more stable indicator of MS over a period of time than biochemical measures (Katzmarzyk et al. 2001). Body fat composition, independently of other factors, has been shown to provide a reliable marker of MS through the life course (Yarbrough et al. 1998; Vanhala et al. 1999; Chen et al. 2000) and across cultures (Okosun et al. 1998; Martins \& Marinho, 2003). The finding that inter-correlations between the different clinical features of MS become closer with age only in individuals who are obese (Chen et al. 2000) suggests that obesity may indeed be the 'defining feature' of MS (Gigolini et al. 1995). The notion that MS can be inferred from knowledge of non-invasive anthropometric factors alone is therefore feasible.

The task becomes less straightforward when the specific anthropometric factors to use are considered. Perhaps the best evidence comes from studies that have used computed tomography scanning to check visceral adiposity against other features of MS. Such studies have indicated that sagittal diameter provides a reliable indicator of blood pressure, lipid profile and insulin resistance in men, which is more closely correlated with factors associated with MS than either waist circumference, waist: hip ratio or BMI in males (Bjorntorp, 2000; Riserus et al. 2004). Of the anthropometric measures, sagittal diameter correlates most closely with visceral fat (Onat et al. 2004). As there is a lack of studies that have assessed the value of sagittal diameter in women and because sagittal diameter is difficult and time-consuming to assess, the method remains unsuitable for use in a large group of individuals.

The extent to which BMI and waist:hip ratio predict clinical features that comprise MS appears to be gender dependent (Ho et al. 2001; Siani et al. 2002; Benetou et al. 2004; Onat et al. 2004). When all anthropometric measures are considered, waist circumference appears to provide the most convenient and reliable anthropometric marker of clustering of clinical features of MS across gender (Okosun et al. 1998, 2000; Siani et al. 2002; Snijder et al. 2004). There may also be regional differences in terms of which anthropometric measures most accurately reflect metabolic change. A recent study carried out in Portugal has found waist:hip ratio to be a better predictor of MS than waist measures alone (Martins \& Marinho, 2003). Both waist:hip ratio and waist circumference will together provide viable and consistent proxy indication of visceral obesity and MS for the purpose of the LIPGENE study.

\section{Conclusions}

The LIPGENE study will consider, in a large sample of >50-year-old Europeans ( $n$ 1500), a novel range of psychological and behavioural traits reflecting activity of various neurochemicals, certain lifestyle, social and demographic factors, and cultural differences therein against anthropometric markers of MS. It will attempt to unravel the relative contribution of each of these factors to the aetiology of MS using multivariate and predictive techniques. The analysis will not only seek to determine causative relationships between variables, but also to identify different constellations of traits and behaviours that underpin MS and may represent separate pathways to CHD and/or type 2 diabetes. The research will also be unique in exploring cross-cultural differences in how psychological factors may bring about obesity and MS. The research also meets a need for a more holistic approach to understanding the psychological and behavioural underpinning and outcomes of MS.

\section{Acknowledgement}

LIPGENE is an Integrated Project (contract no. FOOD-CT-2003-505944) funded through the EU Sixth 
Framework Programme for Research and Technology Development (2004-2009) (http://www.lipgene.tcd.ie).

\section{References}

Almeras N, Despres JP, Villeneuve J, Demers MF, Roy MA, Cadrin C, Mottard JP \& Bouchard RH (2004) Development of an atherogenic metabolic risk factor profile associated with the use of atypical antipsychotics. Journal of Clinical Psychiatry 65, 557-564

Baptista T (1999) Body weight gain induced by anti-psychotic drugs: mechanisms and management. Acta Psychiatrica Scandinavica 100, 3-16.

Barefoot JC, Peterson BL, Dahlstrom WG, Siegler IC, Anderson NB \& Williams RB (1991) Hostility patterns and health implications: correlates of Cook-Medley Hostility Scale Scores in a national survey. Health Psychology 10, $18-24$.

Basu R, Brar JS, Chengappa KNR, John V, Parepally H, Gershon S, Schlicht P \& Kupfer DJ (2004) The prevalence of metabolic syndrome in patients with schizoaffective disorder-bipolar subtype. Bipolar Disorders 6, 314-318.

Benetou V, Bamia C, Trichopoulos D, Mountokalalakis T, Psaltopoulou T \& Trichopoulou A (2004) The association of body mass index and waist circumference with blood pressure depends on age and gender: A study of 10928 non-smoking adults in the Greek EPIC cohort. European Journal of Epidemiology 19, 803-809.

Bjorntorp P (1999) Neuroendocrine perturbations as a cause of insulin resistance. Diabetic Metabolism Research Reviews 15, 427-441.

Bjorntorp P (2000) Do stress reactions cause abdominal obesity and comorbidities? Obesity Reviews 2, 73-86.

Bjorntorp P \& Rosmond R (1999) Hypothalamic origin of the metabolic syndrome X. Annals of the New York Academy of Sciences 892, 297-307.

Bjorntorp P \& Rosmond R (2000) Neuroendocrine abnormalities in visceral obesity. International Journal of Obesity 24, S80-S85

Black PH (2003) The inflammatory response is an integral part of the stress response: implications for atherosclerosis, insulin resistance, type II diabetes and metabolic syndrome X. Brain, Behaviour and Immunity 17, 350-364.

Brindley DN (1995) Role of glucocorticoids and fatty acids in the impairment of lipid-metabolism observed in the metabolic syndrome. International Journal of Obesity 19, S69-S75.

Brown ES, Varghese FP \& McEwan BS (2004) Association of depression with mental illness: does cortisol play a role? Biological Psychiatry 55, 1-9.

Brunner EJ, Hemmingway H, Walker BR, Page M, Clarke P, Juneja M et al. (2002) Adrenocortical, autonomic and inflammatory causes of the metabolic syndrome. Circulation 106, 2659-2665.

Brunner EJ, Marmot MG, Nanchahal K, Shipley MJ, Stansfeld SA, Juneja M \& Alberti KGMM (1997) Social inequality in coronary risk: central obesity and the metabolic syndrome. Evidence from the Whitehall II study. Diabetologia 40, 1341-1349.

Buttriss J (2003) Metabolic syndrome: new research underway. Nutrition Bulletin 28, 381-385.

Chen W, Bao W, Begum S, Elkasabany A \& Srinivasan SR (2000) Age-related patterns of the clustering of cardio-vascular risk variables of Syndrome $\mathrm{X}$ from childhood to young adulthood in a population made up of black and white subjects. The Bogalusa Heart Study. Diabetes 49, 1042-1048.
Cook WW \& Medley DM (1954) Proposed hostility and parasisaic-virtue scales for the MMPI. Journal of Applied Psychology 38, 414-418.

Danesh HB (1977) Anger and fear. American Journal of Psychiatry 134, 1109-1112.

Diamond EL (1982) The role of anger and hostility in essential hypertension and coronary heart disease. Psychological Bulletin 92, 410-433.

Drapeau V, Therrien F, Richard D \& Tremblay A (2003) Is visceral obesity a physiological adaptation to stress? Panminerva Medica 45, 189-195.

Eikelis N, Lambert G, Weisner G, Kaye D, Schlaich M, Morris M, Hastings J, Socratous F \& Esler M (2004) Extra-adipocyte leptin release in human obesity and its relation to symphathoadrenal function. American Journal of Physiology $\mathbf{2 8 6}$ E744-E752.

Esler M, Rumantir M, Wiesner G, Kaye D, Hastings J \& Lambert G (2001) Sympathetic nervous system and insulin resistance: form obesity to diabetes. American Journal of Hypertension 14, S304-S309.

Feldman PJ \& Steptoe A (2003) Psychosocial and socioeconomic factors associated with glycated hemoglobin in non-diabetic middle-aged men and women. Health Psychology 22, 398-405.

Friedman M \& Rosenman RH (1959) Association of a specific overt behaviour pattern with increases in blood cholesterol, blood clotting time, incidence of arcus senilis and clinical coronary artery disease. Journal of the American Medical Association 169, 1286-1296.

Frost A, Eachus J, Sparrow J, Peters TJ, Hopper C, Davey-Smith G \& Frankel S (2001) Vision-related quality of life impairment in an elderly population: associations with age, sex, social class and material deprivation. Eye 15, 739-744.

Gigolini M, Seidell JC, Targher G, Deslypere JP, Ellsinger BM, Charzewska J, Cruz A \& Bjorntorp P (1995) Fasting seruminsulin in relation to components of the metabolic syndrome in European healthy men - the European fat distribution study. Metabolism: Clinical and Experimental 44, 35-40.

Halford JCG (2001) Pharmacology of appetite suppression: implication for the treatment of obesity. Current Drug Targets 2, 353-370.

Haynes SG, Levine S, Scotch N, Feinleib M \& Kannel WB (1980) The relationship of psychological factors to coronary heart disease in the Frammington Study: I. Methods and risk factors. American Journal of Epidemiology 107, 362-383.

Hidvegi T, Hetyesi K, Biro L \& Jermendy G (2001) Education level and clustering of clinical characteristics of metabolic syndrome. Diabetes Care 24, 2013-2016.

Ho SC, Chen YM, Woo JLF, Leung SSF, Lam TH \& Janus ED (2001) Association between simple anthropometric indices and cardiovascular risk factors. International Journal of Obesity 25, 1689-1697.

Horsten M, Mittleman MA, Wamala SP, Schenck-Gustafsson K \& Orth-Gomer K (1999) Social relations and the metabolic syndrome in middle-aged Swedish women. Journal of CardioVascular Risk 6, 391-397.

Katzmarzyk PT, Perusse L, Bergeron J, Despres JP \& Bouchard C (2001) Stability of indicators of the metabolic syndrome from childhood and adolescence into young adulthood: the Quebec Family Study. Journal of Clinical Epidemiology 54, 190-195.

Kiecolt-Glaser JK, McGuire L, Robles TF \& Glaser R (2002) Emotions, morbidity and mortality: New perspectives. Psychoneuroimmunology 53, 83-92.

Kerenyi Z, Tabac AG, Stella P, Bosyak Z, Simon K, Karadi I \& Tamas G (2000) Association between socioeconomic factors and the metabolic syndrome in women with prior gestational diabetes mellitus. Diabetes Care 23, 1444-1446. 
Kinder LS, Carnethon, MR, Palaniappan LP, King AC \& Fortmann SP (2004) Depression and the metabolic syndrome in young adults: findings from the third national health and nutrition examination survey. Psychosomatic Medicine 66, 316-322.

Laaksonen DE, Lakka HM, Lynch J, Lakka TA, Niskanen L, Rauramaa R, Salonen JT \& Kauhanen J (2003) Cardiorespiratory fitness and vigorous leisure-time physical activity modify the association of small size at birth with the metabolic syndrome. Diabetes Care 26, 2156-2164.

Laaksonen DE, Lakka HM, Salonen JT, Niskanen LK, Rauramaa R \& Lakka TA (2002) Low levels of leisure-time physical activity and cardio-respiratory fitness predict development of the metabolic syndrome. Diabetes Care 25, 1612-1619.

Landen M, Baghaei F, Rosmond R, Holm G, Bjorntorp P \& Eriksson E (2004) Dystipiclemia and high waist-hip ratio in women with self reported social anxiety. Psychoneuroendocrinology 29, 1037-1046.

Lawlor DA, Ebrahim S \& Davey-Smith G (2004) The metabolic syndrome and coronary heart disease in older women: findings from the British Women's Heart and Health Study. Diabetic Medicine 21, 906-913.

Lidfeldt J, Nyberg P, Nerbrand C, Samsioe G, Schersten B \& Agardh CD (2003) Socio-demographic and psychosocial factors are associated with features of the metabolic syndrome. The women's health in the Lund Area (WHILA) study. Diabetes, Obesity and Metabolism 5, 106.

McCaffery JM, Niaura R, Todaro JF, Swan GE \& Carmelli D (2003) Depressive symptoms and metabolic risk in adult male twins enrolled in the national heart, lung and blood institute twin study. Psychosomatic Medicine 65, 409-497.

McElroy SL, Kotwal R, Malhotra S, Nelson EB, Keck PE \& Nemeroff CB (2004) Are mood disorders and obesity related? A review for the mental health professional. Journal of Clinical Psychiatry 65, 634-651.

Martins IS \& Marinho SP (2003) The potential of central obesity anthropometric indicators as diagnostic tools. Revista de Saude Publica 37, 760-767.

Meigs JB, D’Agostino RB, Wilson PW \& Cupples LA (1997) Risk variable clustering in the insulin resistance syndrome. Diabetes 46, 1594-1601.

Muldoon MF, Mackey RH, Williams KV, Korytkowski MT, Flory JD \& Manuck SB (2004) Low central nervous system serotonergic responsivity is associated with the metabolic syndrome and physical inactivity. Journal of Clinical Endocrinology and Metabolism 89, 266-271.

Niaura R (2002) Heart disease; high hostility may be more predictive than other factors. Heart Disease Weekly 29 December issue, 7.

Niaura R, Banks SM, Ward KD, Stonay CM, Spiro A, Aldwin CM, Landsberg L \& Weiss ST (2000) Psychosomatic Medicine 62, 7-16.

Nonogaki K (2000) New insights into sympathetic regulation of glucose and fat metabolism. Diabetologia 43, 533-549.

Okosun S, Cooper RS, Rotimi CN, Osotimehin B \& Forrester T (1998) Association of waist circumference with risk of hypertension and type 2 diabetes in Nigerians, Jamaicans and African Americans. Diabetes Care 21, 1836-1839.

Okosun S, Liao YL, Rotimi CN, Prewitt TE \& Cooper S (2000) Abdominal adiposity and clustering of multiple metabolic syndrome in white, black and Hispanic Americans. Annals of Epidemiology 10, 263-270.

Onat A, Avci GS, Barlan MM, Uyarel H, Uzunlar B \& Sansoy V (2004) Measures of abdominal obesity assessed for visceral adiposity and relation to coronary risk. International Journal of Obesity and Related Metabolic Diseases 28, 1018-1025.
Oppert JM, Lahlou N, Laferrere B, Roger M, Basdevant A \& GuyGrand B (1997) Plasma leptin and acute serotonergic stimulation of the corticotropic axis in women who are normal weight or obese. Obesity Research 5, 410-416.

Paffenbarger RS, Wing AL \& Hyde RT (1978) Physical activity as an index of heart attack risk in college alumni. American Journal of Epidemiology 108, 161-175.

Plutchik R (1980) Emotion: A Psychoevolutionary Synthesis. New York: Harper \& Row.

Puttonen S, Keltikangas-Jarvinen L, Ravaja N \& Viikari J (2003) Affects and autonomic cardiac reactivity during experimentally-induced stress as related to precursors of insulin resistance syndrome. International Journal of Behavioural Medicine 10, 106-124.

Raikkonen K, Keltikangas-Jarvinen L, Ladlercreutz H \& Hautanen A (1996) Psychosocial stress and the insulin resistance syndrome. Metabolism 45, 1533-1538.

Raikkonen K, Matthews KA \& Kuller LH (1999a) Anthropometric and psychosocial determinants of visceral obesity in healthy postmenopausal women. International Journal of Obesity 23, 775-782.

Raikkonen K, Matthews KA \& Kuller LH (2002) The relationship between psychological risk attributes and the metabolic syndrome in healthy women: antecedent or consequence? Metabolism 51, 1573-1577.

Raikkonen K, Matthews KA, Kuller LH, Reiber C \& Bunker CH (1999b) Anger, hostility and visceral adipose tissue in healthy post-menopausal women. Metabolism 48, 1146-1151.

Raikkonen K, Matthews KA \& Salomon K (2003) Hostility predicts metabolic syndrome risk factors in children and adolescents. Health Psychology 22, 279-286.

Ravaja N, Keltikangas-Jarvinen L \& Viikari J (1996) Life changes, locus of control and metabolic syndrome precursors in adolescents and young adults: a three-year follow-up. Social Science and Medicine 43, 51-61.

Rennie KL, McCarthy N, Yazdgerdi S, Marmot M \& Brunner E (2003) Association of metabolic syndrome with both vigorous and moderate physical activity. International Journal of Epidemiology 32, 600 .

Riserus U, Arnlov J, Brismar K, Zethelius B, Berglund L \& Vessby B (2004) Sagittal abdominal diameter is a strong anthropometric marker of insulin resistance and hyperproinsulinemia in obese men. Diabetes Care 27, 2041-2046.

Rosmond R, Holm G \& Bjorntorp P (2000) Food-induced cortisol secretion in relation to anthropometric, metabolic and haemodynamic variables in men. International Journal of Obesity 24, 416-422.

Roth JL, Mobarhan S \& Clohisy M (2002) The metabolic syndrome: where are we where do we go? Nutrition Reviews 60, 335-337.

Roy S, Rink C, Khanna S, Phillips C, Bagchi D, Bagchi M \& Sen CK (2004) Bodyweight and abdominal fat gene expression profile in response to a novel hydroxycitric acid-based dietary supplement. Gene Expression 11, 251-262.

Sargent PA, Sharpley AL, Williams C, Goodall EM \& Cowen PJ (1997) 5-HT2C receptor activation decreases appetite and body weight in obese subjects. Psychopharmacology 133, 309-312.

Seematter G, Binnert C, Martin JL \& Tappy L (2004) Relationship between stress, inflammation and metabolism. Current Opinion in Clinical Nutrition and Metabolic Care 7, 169-173.

Siani A, Cappuccio FP, Barba G, Trevisan M, Farinaro E, Iacone R, Russo O, Russo, P, Mancini M \& Strazzullo P (2002) The relationship of waist circumference to blood pressure: the Olivetti Heart Study. American Journal of Hypertension 15, 780-786.

Snijder MB, Zimmet PZ, Visser M, Dekker JM, Seidell JC \& Shaw JE (2004) Independent and opposite associations of waist 
and hip circumferences with diabetes, hypertension and dyslipidemia: the AusDiab Study. International Journal of Obesity 28, 402-409.

Spielberger CD (1983) Manual for the State-Trait Anger Scale (STAS). Palo Alto, CA: Consulting Psychologist's Press.

Steptoe A \& Marmot M (2003) Burden of psychological adversity and vulnerability in middle age: associations with biobehavioural risk factors and quality of life. Psychosomatic Medicine 65, 1029-1037.

Vanhala MJ, Vanhala PT, Keinanen-Kiukaanniemi SM, Kumpusalo EA \& Takala JK (1999) Relative weight gain and obesity as a child predict metabolic syndrome as an adult. International Journal of Obesity 23, 656-659.

Vieta E (2004) Olanzapine in bipolar disorder. Expert Opinion on Pharmacotherapy 5, 1613-1619.

Vitaliano PP, Scanlan JM, Zhang JP, Savage MV, Hirsch IB \& Siegler IC (2002) Heart disease; role of chronic stress clarified. Heart Disease Weekly 16 June issue, 16.

Waldstein SR, Burns HO, Toth MJ \& Poehlman ET (1999) Cardiovascular reactivity and central adiposy in older African Americans. Health Psychology 18, 221-228.

Wallerius S, Rosmond R, Ljung T, Holm G \& Bjorntorp P (2003) Rise in morning saliva cortisol is associated with abdominal obesity in men: a preliminary report. Journal of Endocrinological Investigation 26, 616-619.

Wamala SP, Lynch J, Horsten M, Mittleman MA, SchenckGustafsson K \& Orth-Gomer K (1999) Education and the metabolic syndrome in women. Diabetes Care $\mathbf{2 2}$, 1999-2003.

Ward AMV, Syddall HE, Wood PJ, Dennison EM \& Phillips DIW (2004) Central hypothalamic-pituitary-adrenal activity and the metabolic syndrome: studies using the corticotrophinreleasing hormone test. Metabolism: Clinical and Experimental 53, 720-726.

Weber-Hamann B, Hentschel F, Kniest A, Deuschle M, Colla M, Lederbogen F \& Heuser I (2002) Hypercolesterolemic depression is associated with increased intra-abdominal fat. Psychosomatic Medicine 54, 274-277.

Wellman PJ, Jones SL \& Miller DK (2003) Effects of preexposure to dexfenfluramine, phentermine, dexfenfluramine-phentennine or fluoxetine on sibutramine-induced hypophagia in the adult rat. Pharmacology Biochemistry and Behavior 75, 103-114.

Woodall KL \& Matthews KA (1993) Change in and stability of hostile characteristics: results form a 4-year longitudinal study of children. Journal of Personality and Social Psychology 64, 491-499.

Zimmermann U, Kraus T, Himmerich H, Schuld A \& Pollmacher T (2003) Epidemiology, implications and mechanisms underlying drug-induced weight gain in psychiatric patients. Journal of Psychiatric Research 37, 193-220.

Yarbrough DE, Barrett-Connor E, Kritz-Silverstein D \& Wingard DL (1998) Birth weight, adult weight and girth as predictors of the metabolic syndrome in postmenopausal women. Diabetes Care 21, 1652-1659. 
https://doi.org/10.1079/PNS2005444 Published online by Cambridge University Press 